\title{
Developmental determinants and changing patterns of respiratory outcomes after preterm birth
}

\author{
Steven H. Abman, MD ${ }^{1,{ }^{*}}$ and Simon J. Conway, $\mathbf{P h D}^{2,{ }^{*}}$ \\ ${ }^{1}$ Pediatric Heart Lung Center, Pediatric Pulmonary Medicine, University of Colorado Anschutz \\ Medical Center and Children's Hospital Colorado, Aurora, CO 80045, USA \\ 2Developmental Biology and Neonatal Medicine Program, HB Wells Center for Pediatric \\ Research, Indiana University School of Medicine, Indianapolis, IN 46202, USA
}

\section{Evolution of Bronchopulmonary Dysplasia}

Nearly 50 years ago, Northway and colleagues provided the first clinical, radiologic and pathologic characterization of the chronic lung disease that follows preterm birth, anointing this problem as "bronchopulmonary dysplasia (BPD)," due to key pathologic features of that era (Northway WH et al, 1967). This original report described severe respiratory morbidity and high mortality in relatively late-gestation preterm infants, largely due to the lack of surfactant therapy and insufficient neonatal ventilator care at that time. Improved obstetrical and neonatal care over time has increased survival of even the smallest of immature newborns over time, yet BPD persists as a major problem, occurring in roughly 10,000 infants per year in the USA alone. Breakthroughs with the use of antenatal steroids, surfactant therapy, continuous positive airway pressure (CPAP), improved ventilator technology and strategies, and other interventions, have remarkably improved survival and outcomes, yet survivors of neonatal intensive care still have substantial late respiratory morbidity. Preterm birth and its respiratory sequelae have important health care implications, as infants with BPD require prolonged NICU courses; frequent readmissions during the first two years after discharge for respiratory infections, asthma, and related problems; and have persistent lung function abnormalities and exercise intolerance as adolescents and young adults.(Bland RD and Coalson JJ, 2000; Jobe AH and Bancalari E, 2001; Bancalari E et al, 2001; Jobe AJ, 1999; Charafeddine L et al, 1999; Rojas MA et al, 1995: Laughon $\mathrm{M}$ et al, 1999).

The overall incidence of BPD has not declined over the past decade (Laughon M et al, 2010), but the respiratory course and number of infants with severe BPD has clearly changed with current clinical practice. Infants with chronic lung disease after premature birth have a different clinical course and pathology than had been traditionally observed in infants dying with BPD during the pre-surfactant era (Charafeddine L et al, 1999; Rojas et al, 1995: Laughon M et al, 1999; Smith VC et al, 2005; Hussain E et al, 2000; Coalson JJ, 2000; Jobe AH and Bancalari E, 2001). The classic progressive stages of disease, including

*Address correspondence to: Steven H. Abman, MD, Pediatric Pulmonary Medicine, University of Colorado Denver Anschutz School of Medicine and Children's Hospital Colorado, Mail Stop B395, 13123 East 16th Avenue, Aurora CO 80045. Office phone:

720-777-582, Steven H. Abman Steven.Abman@ucdenver.edu and Simon J. Conway siconway@iupui.edu. 
prominent fibro-proliferative changes, which first characterized BPD are often absent now, and the disease has changed to being predominantly defined as a disruption of distal lung growth, referred to as "the new BPD."(Jobe AH, 1999) In contrast with the past, the "new BPD" often develops in preterm newborns who may have required minimal or even no ventilator support and relatively low inspired oxygen concentrations during the early postnatal days (Charafeddine $\mathrm{L}$ et al, 1999; Rojas MA et al, 1995). At autopsy, the lung histology of infants who die with "the new BPD" displays more uniform and milder injury, but impaired alveolar and vascular growth remain prominent. (Figure 1A,B) The "new BPD" is likely the result of disrupted antenatal and postnatal lung growth, leading to persistent abnormalities of lung architecture and function. Although many of the implications of how these changes in BPD alter long-term pulmonary outcomes remain uncertain, this special issue of BDRA brings together a diverse mix of new BPD reviews and primary data as a window into the remarkable progress and current state of the field.

Despite years of investigation, clinical interventions that have been proven to reduce the risk for or severity of BPD remain rare. We continue to work towards improving postnatal care of preterm infants through the application of "best practice" strategies yet clinical practices and the incidence of new BPD still varies widely between centers (Walsh MA et al, 2007). Such approaches as less invasive respiratory support, avoidance of excessive hyperoxia, greater use of lung protective strategies, more aggressive nutrition, the use of vitamin A or caffeine, may improve outcomes but these strategies are not routinely used across centers. Recent studies suggest that delivery room practices regarding oxygen use, early institution of nasal CPAP and surfactant and the avoidance of large tidal volume breaths with bag-mask ventilation during resuscitation may also be critical determinants of outcomes, but as discussed by Drs. Deepak and Bancalari, many clinical interventions and their efficacy remain incompletely studied (Deepak J and Bancalari E, 2014).

\section{Changing Epidemiology of BPD}

As Northway originally observed, BPD has diverse, multifactorial etiologies, including hyperoxia, ventilator-induced lung injury, inflammation and infection (Northway WH et al, 1967; Bonikos DS et al, 1976; Crapo JD et al, 1978). In addition to the traditional effects of postnatal injury, epidemiologic studies over the past decade have further identified critical perinatal factors that are strongly linked with high risk for BPD. As discussed by Drs. Jensen and Schmidt, BPD likely begins in utero, as intrauterine growth restriction (IUGR), lack of antenatal corticosteroids, chorioamnionitis, maternal smoking, placental insufficiency and other antenatal factors are strongly associated with BPD risk (Jensen E and Schmidt B, 2014; van Marter LJ et al, 1990; Zeitlin J et al, 2010; Bose C et al, 2009; Lee HJ et al, 2010; Hansen AR et al, 2010; Tang JR et al, 2010; Rozance PJ et al, 2011). Studies in diverse translational studies using animal models of IUGR, preeclampsia, chorioamnionitis and other stresses, have provided biologic plausibility that support mechanisms underlying these epidemiologic findings (van Marter LJ et al, 1990; Zeitlin J et al, 2010; Bose C et al, 2009; Lee HJ et al, 2010; Hansen AR et al, 2010; Tang JR et al, 2010; Rozance PJ et al, 2011). Preclinical studies suggest that lung injury due to each of these adverse stimuli is at least partly mediated through increased oxidative stress that further augments inflammation, promotes lung injury and impairs growth factor signaling pathways (Davis JM et al, 1993; 
Davis JM et al, 2003). Animal models further suggest that antenatal factors, even independent of hyperoxia, mechanical ventilation and other postnatal events, are sufficient to alter lung structure through infancy and into adulthood.

Further studies are needed to determine how different etiologic mechanisms contribute to the development of new BPD, and such studies may lead to novel interventions for diseasespecific mechanisms underlying new BPD in the clinical setting. Additional insights into developmental mechanisms underlying normal lung growth and pathogenic mechanisms that disrupt signaling and cause sustained impairments of lung structure and function are essential for understanding respiratory outcomes after preterm birth.

\section{Developmental Mechanisms of Altered Lung Development in new BPD}

BPD results from complex interactions between the degree of prematurity with early disruption of lung development, the response to acute lung injury, and mechanisms of lung repair and regeneration. Notably, new BPD primarily occurs in babies born under 29 weeks gestation, with rates ranging from 40-60\%. Preterm birth near the limits of viability at 2324 weeks through 28 weeks gestation disrupts the normal progression of lung development that takes place during the late canalicular, saccular and alveolar stages of normal lung development. This timing of premature birth clearly precedes the rapid increase in airway septation and vessel growth that normally accelerates during late gestation. Even relatively mild increases in oxygen tension may be sufficient to induce inhibitory effects on lung growth in the setting of extreme prematurity. Factors implicated in aberrant lung development associated with new BPD include a fragile, structurally and biochemically immature lung, which enhances susceptibility secondary injury, infection, inflammation, oxidative stress, mechanical injury associated with positive pressure respiratory support, apnea and inadequate nutrition. Supportive evidence suggests that genetic and epigenetic factors modulate the severity to these insults, and that individual responses are further altered by distinct causal factors that dominate in different patients who develop new BPD.

As presented in this Special Issue, multiple interactive signaling pathways have been implicated in the pathogenesis of new BPD from preclinical and clinical studies alike.

Hadchouel and coworkers provide an excellent overview of molecular mechanisms that alter lung development in new BPD (Hadchouel A et al, 2014). Mechanisms that lead to abnormal alveolarization and the development of a dysmorphic pulmonary circulation are discussed in detail. Importantly, these authors cite essential elements that may link basic studies with potential future therapeutic strategies. Strong evidence exists for critical roles of several candidate factors, including those associated with lung matrix remodeling (such as matrix metalloproteinases), growth factors that promote alveolarization (including plateletderived growth factor) and pro-angiogenic pathways (e.g., vascular endothelial growth factor signaling) during normal lung development, and how altered expression or manipulation of these factors in injury animal models (Figure 1C,D) can result in abnormal lung structure that mimics human new BPD.

These concepts are further developed in the thorough review of alveolar-capillary development and repair mechanisms in new BPD from Drs. Ahlfeld and Conway (Ahlfeld S 
and Conway SJ, 2014). These authors discuss links between histologic evidence of disrupted alveolar-capillary structure in human infants with physiologic impairment of gas exchange. Past work has shown a marked proliferation of vessels accompanying increased lung parenchyma volume and surface area between 22-32 weeks gestation in the normal fetus, which then continues to grow until term, albeit at a much slower rate (Thibeault DW et al, 2004). In marked contrast, patients dying with severe new BPD even late during infancy generally have a dramatic reduction in septation and capillary volume, demonstrating sustained abnormalities of distal lung architecture. They further highlight novel physiologic assessments of diffusion capacity in human infants as providing physiologic proof of the functional aspects of reduced surface area and discuss potential applications in animal models. Although the new BPD has been characterized as an arrest of lung and vascular growth, most of these observations were based on lung histology and evidence was lacking that provided direct physiologic and functional data to support this finding. Recent work from Tepper and colleagues has demonstrated the important finding of reduced lung surface area in infants with new BPD by utilizing assessments of diffusion capacity (Balinotti JE et al, 2010). Thus, established BPD is primarily characterized by reduced surface area and heterogeneous lung units, in which regional variations in airway resistance and tissue compliance lead to highly variable time constants throughout the lung.

The important roles of paracrine cellular and extracellular matrix interactions, especially with regard to mesenchymal progenitors during alveolar development are the focus of Dr. McGowan's insightful review (McGowan S, 2014). A strong argument is made for the essential role of an incredibly rich and dynamic mesenchymal environment during development, which includes key interactions among diverse cells such as endothelium, pericytes, fibroblasts and others, with neighboring epithelium. Clearly, the establishment of normal lung structure is dependent upon complex cross-talk signaling mechanisms within the developing mesenchyme as well as between mesenchyme and epithelium, and between cells and their extracellular matrix.

Drs. Collins and Thebaud discuss the key roles of diverse endothelial and mesenchymal progenitors in new BPD and potential therapeutic implications (Collins $\mathbf{J}$ and Thebaud B, 2014). Advances in stem cell biology have sparked interest in the reparative potential of endothelial progenitor cells (EPCs). Preclinical studies suggest that lung and circulating EPCs are decreased in experimental new BPD (Balasubramaniam V et al, 2010). Clinical studies suggest that reduced EPCs in cord blood are strongly associated with risk for the development of moderate to severe new BPD (Baker CD et al, 2012; Borghesi A et al, 2009). Mesenchymal stem cells (MSC) preserve lung development in rodent models of new BPD (Aslam M et al, 2009; van Haaftern T et al, 2009). These effects do not require MSC engraftment and are mediated through release of MSC-derived products [the "secretome" (Abman SH and Matthay MA, 2009)], which may lead to novel interventions for BPD prevention or treatment. However, much remains to be learned regarding how progenitor cells contribute to normal lung development, whether decreased progenitor cell number or impaired function actually contributes to new BPD and how to best apply such strategies to human preterm infants at risk for (prevention) or with established (treatment) new BPD. 
In addition, two articles provide striking examples of highly specific critical signaling pathways that are implicated in the pathobiology of new BPD. First, preclinical and clinical studies over the years have strongly implicated lung inflammation and host immune responses in the pathobiology of new BPD. For example, hyperoxia causes sustained neutrophil-dominant inflammation in animal models and tracheal samples from infants who develop new BPD (Ogden BE et al, 1984). Similarly, prenatal inflammation caused by chorioamnionitis is generally linked to increased risk for new BPD in human infants (Watterberg KL, et al, 1996) and causes BPD-like changes in lung histology in animal models, even in the absence of postnatal injury (Tang JR et al, 2010). The nuclear factor K$\mathrm{B}(\mathrm{NFkB})$ family of transcription factors that are ubiquitously expressed throughout the lung and have been shown to play critical roles in cell growth, survival and inflammation (Alvira C, 2014). Based on past work by Dr. Alvira, NFkB signaling plays an essential role during normal lung development yet further contributes to the pathogenesis of inflammationmediated disruption of lung growth. This "double-edged sword" nature of NFkB reflects its complex biology and its ability to regulate a plethora of down-stream mediators. Insights into the regulation of NFkB -related activities will likely lead to future interventions to modulate outcomes of preterm infants at risk for new BPD.

Another example for the role of a specific factor and signaling pathway in the pathogenesis of new BPD is represented by endothelial monocyte activating polypeptide II (EMAP II). As reviewed by Drs. Lal and Schwartz, EMAP II highlights an exciting and growing story around the important role for angiogenesis in the etiology of BPD (Lal CV and Schwarz M, 2014). Experimental studies have previously shown that early injury to the developing lung can impair angiogenesis, which further contributes to decreased alveolarization and simplification of distal lung airspaces (the "vascular hypothesis") (Abman SH, 2001). For example, VEGF, an endothelial cell-specific survival factor, stimulates angiogenesis and protects against endothelial injury. Pharmacological and genetic VEGF inhibition during perinatal development decreases alveolarization and pulmonary arterial density, (Jakkula M et al, 2000; Thebaud B et al, 2005), features encountered in clinical BPD. Reduced VEGF and VEGF receptor (VEGFR) have been reported in lungs of infants with fatal BPD (Bhatt AJ et al, 2001; Lassus P et al, 2001). In this context, EMAP II has been shown to have antiangiogenic properties and is increased in the lungs of infants dying with severe BPD (Lal CV and Schwarz M, 2014). This paper highlights how this novel pathway may become a key target for therapeutic interventions to reduce the risk or severity of new BPD.

Finally, the clinical consequences of pulmonary vascular injury are discussed by Drs. Ambalavanan and Mourani, who review the important problem of pulmonary hypertension in BPD infants (Ambalavanan N and Mourani PM, 2014). Pulmonary hypertension is strongly associated with poor survival in new BPD, either as a cause of death or as a biomarker for more severe lung disease. This paper presents the "state-of-the-art" regarding our current understanding of the epidemiology, pathophysiology and treatment of PH in BPD. Abnormalities of the lung circulation in BPD are not only related to the presence or absence of $\mathrm{PH}$, but more broadly, pulmonary vascular disease after premature birth as manifested by decreased vascular growth and structure also contributes to the abnormal cardiopulmonary physiology of new BPD, including sustained impairment of surface area for gas exchange. 


\section{Spectrum of Respiratory Outcomes after Preterm Birth}

Although the severity of new BPD is associated with a prolonged need for respiratory support, oxygen therapy and prolonged NICU hospitalizations, major respiratory morbidities extend throughout infancy, childhood and perhaps, adult life. Infants with new BPD are at substantial risk for recurrent respiratory exacerbations, frequent hospitalizations with viral infections, the need for asthma medications, exercise intolerance and related problems. Although most infants show improvement with time, recent studies have shown persistent abnormalities of lung function and structure in adult survivors of BPD. In fact, lung function in some infants may worsen during infancy (Hoofhuis $\mathrm{W}$ et al, 2002). A study of 86 survivors of extreme preterm birth ( $<1,000$ grams or gestational age 28 weeks) at 10 or 18 years of age found significantly higher high resolution computerized tomography (HRCT) scores as well as more opacities and hypo-attenuated areas in subjects with a history of moderate or severe new BPD than in those with a history of no or mild BPD (Auckland SM et al, 2009). Similarly, abnormal HRCT scans with emphysematous changes were reported in 19 subjects aged 17-33 years born at $<1,500$ grams with the diagnosis of moderate-tosevere BPD, and these abnormal CT scans were correlated with abnormalities in pulmonary function (Wong PM et al, 2008). Thus, there is evidence that severe BPD is associated with life-long changes in pulmonary structure and function. However, more studies are needed to accurately determine the long-term course of premature neonates with severe new BPD and their relative contribution to the growing adult population.

Interestingly, there appears to be wide variability in late respiratory outcomes in preterm cohorts. For example, a recent study of distal lung structure as assessed by hyperpolarized helium magnetic resonance imaging (MRI) studies suggested that survivors of new BPD had similar distal airspace structure as former preterm infants without a diagnosis of new BPD and control term infants when studied during early adolescence (Narayanan M et al, 2013). Although these studies did not provide serial measurements of subjects with BPD over time, it appears that infants may have the ability to adapt and grow distal lung throughout childhood, and that there remains substantial ability for late recovery. Insights into mechanisms or mediators that may promote accelerated recovery and late compensatory growth (so-called "resilience factors") require further investigation.

\section{Conclusions}

BPD remains one of the most important causes of adverse health outcomes for infants born prematurely. It is increasingly apparent that lung injury sustained in utero and shortly after birth is a key determinant of later childhood and adult lung health and disease. Despite many advances in perinatal care, few specific interventions have been proven as effective in reducing the risk for or severity of new BPD. Insights into basic mechanisms of lung development are essential for help in providing novel strategies for future interventions. The social and economic impacts of impairment of lung health in subjects with BPD warrant a renewed emphasis on research to prevent new BPD. Despite decades of promising findings, strategies that effectively prevent new BPD are largely lacking. Continued translational research, including "bench to bedside" approaches with animal models that best reflect the evolving clinical epidemiology of new BPD, will likely be fruitful. In addition, high quality 
population-based studies are needed to better "endo-type" preterm infants at risk for new BPD, and may help to identify epigenetic, genetic and proteomic biomarkers that predict risk, provide insights into disease mechanisms or lead to better surrogate outcomes for clinical trials. Finally, the need to develop better tools to improve physiologic and lung imaging are vital for enhancing our understanding of disease course and outcomes and to provide improved endpoints for better investigations to prevent new BPD and improve longterm pulmonary outcomes.

As Guest Editors, we are thoroughly indebted to the authors for their expertise and informed contributions, and hope that you will find this collection informative and stimulating.

\section{Acknowledgments}

Studies were supported, in part, Riley Children's Foundation and National Institutes of Health HL115619 (to S.J.C.); and HL68702, HL085703 (to S.H.A.).

\section{References}

Abman SH. BPD: a vascular hypothesis. Am J Resp Crit Care Med. 2001; 164:1755-6. [PubMed: 11734417]

Abman SH, Matthay MA. Mesenchymal stem cells in the prevention of BPD: delivering the secretome. Am J Respir Crit Care Med. 2009; 180:1039-41. [PubMed: 19923401]

Ahlfeld S, Conway SJ. Inhibited alveolar-capillary development and potential for repair in BPD. Birth Defects Research Part A: Clinical and Molecular Teratology. 2014 in press.

Alvira C. Nuclear factor kappa B signaling in lung development and disease: one pathway, numerous functions. Birth Defects Research Part A: Clinical and Molecular Teratology. 2014 in press.

Ambalavanan N, Mourani P. Pulmonary hypertension in BPD. Birth Defects Research Part A: Clinical and Molecular Teratology. 2014 in press.

Aslam M, Baveja R, Liang OD, et al. Bone marrow stromal cells attenuate lung injury in a murine model of neonatal chronic lung diseae. Am J Respir Crit Care Med. 2009; 180:1122-30. [PubMed: 19713447]

Aukland SM, Rosendahl K, Owens CM, Fosse KR, Eide GE, Halvorsen T. Neonatal bronchopulmonary dysplasia predicts abnormal pulmonary HRCT scans in long-term survivors of extreme preterm birth. Thorax. 2009; 64:405-410. [PubMed: 19158126]

Baker CD, Balasubramaniam V, Mourani PM, Sontag MK, Black CP, Ryan SL, Abman SH. Cord blood angiogenic progenitor cells are decreased in preterm infants who develop BPD. Eur Respir J. 2012; 40:1516-22. [PubMed: 22496315]

Balasubramaniam V, Ryan S1, Seedorf G, Roth EV, Heumann TR, Ingram DE, Yoder MC, Hogan CJ, Markham NE, Abman SH. Bone marrow derived angiogenic cells restore alveolar and vascular structure after neonatal hyperoxia in infant mice. Am J Physiol. 2010; 298:L315-23.

Balinotti JE, Chakr VC, Tiller C, et al. Growth of lung parenchyma in infants and toddlers with chronic lung disease of infancy. Am J Respir Crit Care Med. 2010; 181:1093-7. [PubMed: 20133928]

Bancalari E, Abdenour GE, Feller R, Gannon J. Bronchopulmonary dysplasia: clinical presentation. J Pediatr. 1979; 95:819-23. [PubMed: 385815]

Bancalari, E.; Gonzalez, A. Clinical course and lung function abnormalities during development of chronic lung disease. In: Bland, RD.; Coalson, JJ., editors. Chronic lung disease in early infancy. NY: Marcel Dekker; 2000.

Bhatt AJ, Pryhuber GS, Huyck H, Watkins RH, Metlay LA, Maniscalco WM. Disrupted pulmonary vasculature and decreased VEGF, flt- 1 and Tie 2 in human infants dying with bronchopulmonary dysplasia. Am J Respir Crit Care Med. 2001; 164:1971-80. [PubMed: 11734454]

Bland, RD.; Coalson, JJ. Chronic lung disease in early infancy. NY: Marcel Dekker; 2000. 
Bonikos DS, Benson KG, Northway WHJ. Oxygen toxicity in the newborn. The effect of chronic continuous 100\% oxygen exposure on the lung of newborn mice. Am J Pathol. 1976; 85:623-50. [PubMed: 998734]

Borghesi A, Massa M, Campanelli R, et al. Circulating endothelial progenitor cells in preterm infants with BPD. Am J Respir Crit Care Med. 2009; 180:540-6. [PubMed: 19574444]

Bose C, van Marter LJ, Laughon M, et al. Fetal growth restriction and chronic lung disease among infants born before the $28^{\text {th }}$ week of gestation. Pediatrics. 2009; 124:e450-8. [PubMed: 19706590]

Charafeddine L, D'Angio CT, Phelps DL. Atypical chronic lung disease patterns in neonates. Pediatrics. 1999; 103:759-60. [PubMed: 10103299]

Coalson, JJ. Pathology of chronic lung disease of early infancy. In: Bland, RD.; Coalson, JJ., editors. Chronic lung disease of early infancy. NY: Marcel Dekker; 2000. p. 85-124.

Collins J, Thebaud B. Progenitor cells of the distal lung and their potential role in neonatal lung disease. Birth Defects Research Part A: Clinical and Molecular Teratology. 2014 in press.

Crapo JD, Peters-Golden M, Marsh-Salin J, et al. Pathologic changes in the lungs of oxygen-adapted rats. A morphometric analysis. Lab Invest. 1978; 39:640-53. [PubMed: 739764]

Davis JM, Parad RB, Michele T, et al. Pulmonary outcome at one year corrected age in premature infants treated at birth with recombinant CuZn superoxide dismutase. Pediatrics. 2003; 111:46976. [PubMed: 12612223]

Davis JM, Rosenfeld WN, Sanders RJ, Gonenne A. Prophylactic effects of recombinant human superoxide dismutase in neonatal lung injury. J Appl Physiol. 1993; 74:2234-41. [PubMed: 8335553]

Deepak J, Bancalari E. BPD- Clinical perspective. Birth Defects Research Part A: Clinical and Molecular Teratology. 2014 in press.

Hadchouel A, Franco-Montoya M-L, Delacourt C. Altered lung development in BPD. Birth Defects Research Part A: Clinical and Molecular Teratology. 2014 in press.

Hansen AR, Barnes CM, Folkman J, McElrath TF. Maternal preeclampsia predicts the development of BPD. J Pediatr. 2010; 156:532-6. [PubMed: 20004912]

Hofhuis W, Huysman MW, van der Wiel EC, Holland WP, Hop WC, Brinkhorst G, de Jongste JC, Merkus PJ. Worsening of $\mathrm{V}^{\prime}$ maxFRC in infants with chronic lung disease in the first year of life: a more favorable outcome after high-frequency oscillation ventilation. Am J Respir Crit Care Med. 2002; 166:1539-1544. [PubMed: 12471071]

Hussain AN, Siddiqui NH, Stocker JT. Pathology of arrested acinar development in postsurfactant bronchopulmonary dysplasia. Hum Pathol. 1998; 29:710-17. [PubMed: 9670828]

Jakkula M, Le Cras TD, Gebb S, et al. Inhibition of angiogenesis decreases alveolarization in the developing rat lung. Am J Physiol Lung Cell Mol Physiol. 2000; 279:L600-607. [PubMed: 10956636]

Jensen E, Schmidt B. Epidemiology of BPD. Birth Defects Research Part A: Clinical and Molecular Teratology. 2014 in press.

Jobe AH. The new BPD: an arrest of lung development. Pediatr Res. 1999; 46:641-43. [PubMed: 10590017]

Jobe AH, Bancalari E. Bronchopulmonary Dysplasia. Am J Respir Crit Care Med. 2001; 163:1723-29. [PubMed: 11401896]

Lal CV, Schwarz M. Vascular mediators in chronic lung disease of infancy: role of endothelial monocyte activating polypeptide II (EMPA II). Birth Defects Research Part A: Clinical and Molecular Teratology. 2014 in press.

Lassus P, Turanlahti M, Heikkila P, et al. Pulmonary VEGF and Flt-1 in fetuses, in acute and chornic lung disease, and in persistent pulmonary hypertension of the newborn. Am J Respir Crit Care Med. 2001; 164:1981-7. [PubMed: 11734455]

Laughton M, Alfred EN, Bose C, et al. Patterns of respiratory distress during the first 2 postnatal weeks in extremely premature infants. Pediatrics. 2010; 123:1124-31.

Lee HJ, Kim EK, Kim HS, et al. Chorioamnionitis, respiratory distress syndrome and BPD in extremely low birth weight infants. J Perinatology. 2010:1-5. 
McGowan S. Paracrine cellular and extracellular matix interactions with mesenchymal progenitors during pulmonary alveolar septation. Birth Defects Research Part A: Clinical and Molecular Teratology. 2014 in press.

Narayanan M, Beardsmore CS, Owers-Bradley J, et al. Catch up alveolarization in ex-preterm children: evidence from 3(He) magnetic resonance. Am J Respir Crit Care Med. 2013; 187:11049. [PubMed: 23491406]

Northway WH Jr, Rosan RC, Porter DY. Pulmonary disease following respiratory therapy of hyaline membrane disease. N Engl J Med. 1967; 276:357-68. [PubMed: 5334613]

Ogden BE, Murphy SA, Saunders GC, et al. Neonatal lung neutrophils and elastase/proteinase inhibitor imbalance. Am Rev Respir Dis. 1984; 130:817-2. [PubMed: 6333839]

Rojas MA, Gonzalez A, Bancalari E, et al. Changing trends in the epidemiology and pathogenesis of chronic lung disease. J Pediatr. 1995; 126:605-10. [PubMed: 7699543]

Rozance PJ, Seedorf GJ, Brown A, Gien J, Tang J-R, Abman SH. Intrauterine growth restriction decreases pulmonary alveolar and vessel growth and causes pulmonary artery endothelial cell dysfunction in vitro. Am J Physiol Lung. 2011; 301(6):L860-71.

Smith VC, Zupancic JAF, McCormick MC, et al. Trends in severe bronchopulmonary dysplasia rates between 1994 and 2002. J Pediatr. 2005; 146:469-73. [PubMed: 15812448]

Tang JR, Seedorf G, Muehlethaler V, et al. Moderate hyperoxia accelerates lung growth and attenuates pulmonary hypertension in infant rats after exposure to intra-amniotic endotoxin. Am J Physiol: Lung. 2010; 299:L735-48.

Thebaud B, Ladha F, Michelakis ED, et al. VEGF gene therapy increases survival, promotes lung angiogenesis, and prevents alveolar damage in hyperoxia-induced lung injury: evidence that angiogenesis participates in alveolarization. Circulation. 2005; 112:2477-86. [PubMed: 16230500]

Thibeault DW, Mabry SM, Norberg M, Truog WE, Ekekezie II. Lung microvascular adaptation in infants with chronic lung disease. Biol Neonate. 2004; 85:273-82. [PubMed: 14739556]

Van Haaften T, Byrne R, Bonnet S, et al. Airway delivery of mesenchymal stem cells prevents arrested alveolar growth in neonatal lung injury in rats. Am J Respir Crit Care Med. 2009; 180:1131-42. [PubMed: 19713449]

Van Marter LJ, Leviton A, Kuban KC, Pagano M, Allred EN. Maternal glucocorticoid therapy and reduced risk of bronchopulmonary dysplasia. Pediatrics. 1990; 86:331-6. [PubMed: 2201940]

Walsh M, Laptook A, Kazzi SN, Engle WA, Yao Q, Rasmussen M, Buchter S, Heldt G, Rhine W, Higgins R, et al. A cluster-randomized trial of benchmarking and multimodal quality improvement to improve rates of survival free of bronchopulmonary dysplasia for infants with birth weights of less than 1250 grams. Pediatrics. 2007; 119:876-890. [PubMed: 17473087]

Watterberg KL, Demers LM, Scott SM, Murphy S. Chorioamnionitis and early lung inflammation in infants in whom bronchopulmonary dysplasia develops. Pediatrics. 1996; 97:210-215. [PubMed: 8584379]

Wong PM, Lees AN, Louw J, et al. Emphysema in young adult survivors of moderate-to-severe bronchopulmonary dysplasia. Eur Respir J. 2008; 32:321-8. [PubMed: 18385172]

Zeitlin J, El Ayoubi M, Jarreau PH, et al. Impact of fetal growth restriction on mortality and morbidity in a very preterm birth cohort. J Pediatr. 2010; 157:733-9. [PubMed: 20955846] 

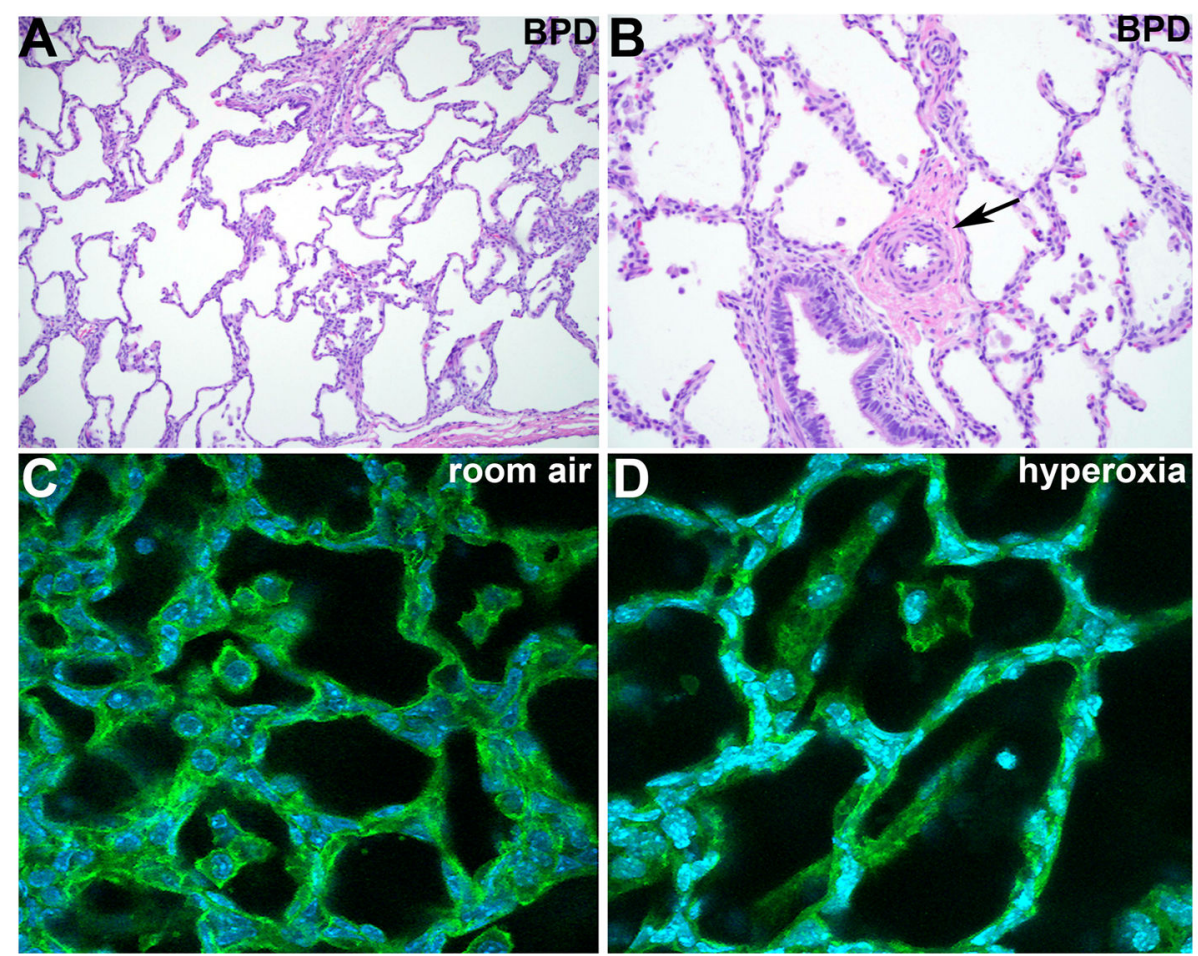

Figure 1. Histological presentation of new BPD

$(\mathbf{A}, \mathbf{B})$ Histology of a patient with fatal new BPD, demonstrating increased distal airspaces with decreased sepatation and reduced alveolarization (A); as well as pulmonary vascular wall thickness is present in small arteries (arrow in B), suggestive of pulmonary hypertension. (C,D) Confocal images of postnatal day 7 mouse lungs exposed to either room air (C) or $85 \% \mathrm{O}_{2}$ hyperoxia (D) from birth onwards. Note that the hyperoxic lung exhibits reduced alveolarization, exemplifying the alterations in distal airspace that mimics new BPD, a chronic lung disease characterized by impaired gas exchange commonly found in extremely premature infants exposed to mechanical ventilation and oxygen supplementation. Nuclei are stained with DAPI (blue) and green signal is extracellular matrix autofluorescence. 